\title{
Synthesis of ultra-small mordenite zeolite nanoparticles
}

\author{
Yi Xu${ }^{1}$, Xuefeng Shen ${ }^{1}$, Cheng Peng ${ }^{2}$, Yue $\mathrm{Ma}^{3}$, Lu Han ${ }^{1,4}$, Peng $\mathrm{Wu}^{3}$, Honggen Peng ${ }^{2 *}$ and \\ Shunai Che $\mathrm{C}^{1,4^{*}}$
}

\begin{abstract}
The mordenite (MOR) nanoparticles (MNPs) with ultra-small crystallites $(\sim 30 \mathrm{~nm})$ were synthesized by using tetraethylammonium bromide (TEAB) as structure directing agent at low temperature $(403 \mathrm{~K})$. The formation of MNPs was considered to be due to high concentration of TEAB and occurrence of limiting Ostwald ripening at low temperature. The MNPs exhibited not only higher catalytic activity at low temperature for selective catalytic reduction of $\mathrm{NO}_{x}$ but also higher catalytic activity and longer lifetime for disproportionation of toluene than conventional MOR (cMOR) bulk crystals.
\end{abstract}

Keywords: zeolite, mordenite, nanoparticles, catalyst

\section{INTRODUCTION}

Zeolites possessing crystalline frameworks and ordered networks of microspores have been widely used as industrial catalysts, ion-exchange materials, and adsorbents [1-4]. Nano-sized zeolites are crucial industrial catalysts and adsorbent because of less diffusion limitations compared to micrometer-sized ones [5]. Synthesis of nanoparticles of ZSM-5, EMT and FAU has been previously reported [6-8]. Mordenite (MOR) is a zeolite with $12 \mathrm{MR}$ and $8 \mathrm{MR}$ channels that have $c$ direction elongation and run one-dimensionally along the $c$-axis; therefore, MOR crystals with ultrashort $c$-direction can decrease the diffusion limitations [9]. Most of the reports on the synthesis of MOR focus on the increase of $\mathrm{Si} / \mathrm{Al}$ ratio and the reducing of crystal size [10-12]. A series of Ti-MOR zeolites with different crystal morphologies from nanoparticle to nanorod owning different catalytic activities have been synthesized by Wu's group [13]. Ryoo and coworkers [14] succeeded in synthesizing MOR nanoparticles with a prolinol derivative, trivalent surfactant. However, it is rarely reported the synthesis of MOR crystals with tetraethylammonium bromide (TEAB) as structure directing agent (SDA) at $403 \mathrm{~K}$.

The crystallization process at low temperature decreases the kinetic polymerization of silicate and aluminate to obtain highly uniform precursor particles and limits Ostwald ripening [8]. In addition, the high concentration of organic template or SDA could provide abundant crystal nuclei, which lead to small crystallites with a narrow particle size distribution. Here, we synthesized MOR nanoparticles (MNPs) with a high concentration of TEAB and at a relatively lower temperature $(403 \mathrm{~K})$ than common synthetic temperature (443 K) [15]. The catalytic activity of MNPs for selective catalytic reduction (SCR) of $\mathrm{NO}_{x}$ with $\mathrm{NH}_{3}$ as reductant and disproportionation of toluene were investigated.

\section{EXPERIMENTAL SECTION}

\section{Chemicals}

Colloidal silica (30 wt.\%) as silicon source was purchased from Alfa Aesar. Sodium hydroxide $(\mathrm{NaOH},>96 \%)$ and TEAB were purchased from Sinopharm Chemical Reagent Co., Ltd. Sodium aluminate $\left(\mathrm{NaAlO}_{2}\right)$ was purchased from Aladdin Reagent Co., Ltd.

\section{Synthesis of zeolite materials}

In a typical synthesis of MNPs, $0.24 \mathrm{~g} \mathrm{NaOH}, 0.21 \mathrm{~g}$

\footnotetext{
${ }^{1}$ School of Chemistry and Chemical Engineering, State Key Laboratory of Metal Matri Composites, Shanghai Jiao Tong University, Shanghai, 200240, China

${ }^{2}$ Institute of Applied Chemistry, College of Chemistry, Nanchang University, Nanchang 330031, China

${ }^{3}$ Shanghai Key Laboratory of Green Chemistry and Chemical Processes, School of Chemistry and Molecular Engineering, East China Normal University, Shanghai 200062, China

${ }^{4}$ School of Chemical Science and Engineering, Tongji University, Shanghai 200092, China

* Corresponding authors (emails: chesa@sjtu.edu.cn (Che S); penghonggen@ncu.edu.cn (Peng H))
} 

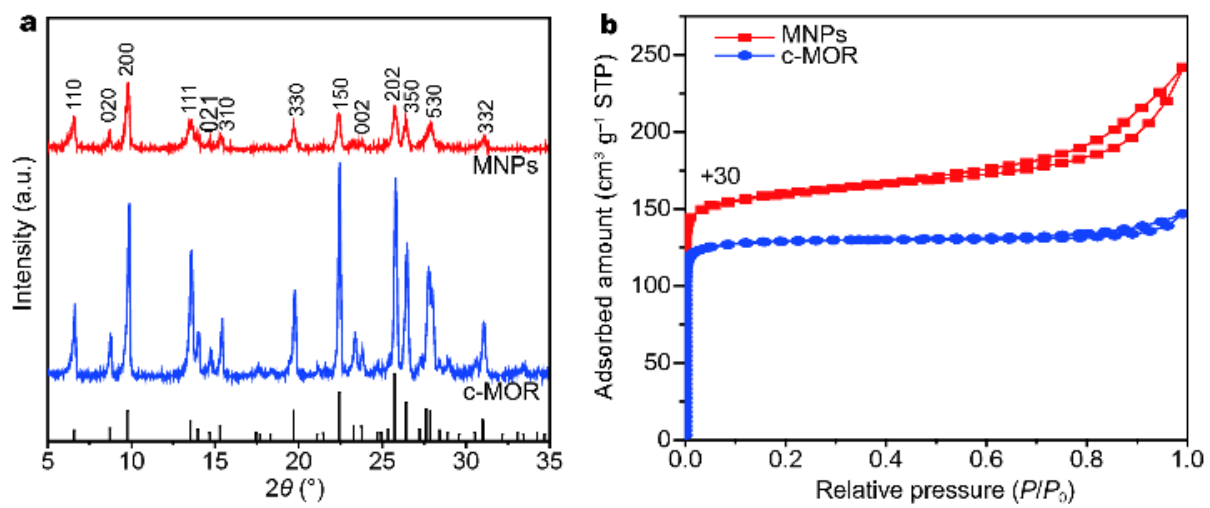

Figure 1 XRD patterns (a) and $\mathrm{N}_{2}$ adsorption-desorption isotherms (b) of calcined MNPs and c-MOR.

TEAB, $0.087 \mathrm{~g} \mathrm{NaAlO}_{2}$ and $6.88 \mathrm{~g}$ water were mixed together. Then $3.07 \mathrm{~g}$ of colloidal silica was added to obtain an aluminosilicate gel by vigorous stirring for $3 \mathrm{~h}$ at $298 \mathrm{~K}$. The gel was transferred to a stainless steel autoclave and the sealed autoclave was placed in an air oven maintained at $403 \mathrm{~K}$ for four days. The crystalline white solid was filtered, washed and dried at $353 \mathrm{~K}$ in air for $6 \mathrm{~h}$, and subsequently calcined in air at $823 \mathrm{~K}$.

\section{Characterizations}

Powder X-ray diffraction (XRD) patterns were recorded on a Rigaku X-ray diffractometer D/max-IIIA equipped with a $\mathrm{Cu} \mathrm{Ka}$ radiation $(40 \mathrm{kV}, 30 \mathrm{~mA})$. The scanning electron microscopy (SEM) was conducted on a JEOL JSM-7800F electron microscope. The Fourier transform infrared spectroscopy (FT-IR) spectra were recorded using a Perkin-Elmer Spectrum 100 FT-IR spectrometer. Thermogravimetric analysis (TG) was performed with a Perkin-Elmer TGA7. The ratios of $\mathrm{Si} / \mathrm{Al}$ in the samples were determined from the results of inductively coupled plasma optical emission spectrometer (ICP-OES) (Thermo Jarrell Ash IRIS Advange 1000). The nitrogen adsorption-desorption isotherms were measured at $77 \mathrm{~K}$ using an ASAP 2460 analyser. The specific surface area was calculated by the Brunauer-Emmett-Teller (BET) method.

\section{Catalysis}

The SCR of NO with $\mathrm{NH}_{3}$ as reductant was selected as the model reaction after supported $\mathrm{Cu}$ active species. $\mathrm{Cu} /$ MOR were prepared via traditional ion-exchange method. $1 \mathrm{~g}$ MOR zeolite, $10 \mathrm{~g} \mathrm{NH}_{4} \mathrm{NO}_{3}$ and $30 \mathrm{~g}$ water were mixed together and stirred at $353 \mathrm{~K}$ for $12 \mathrm{~h}$ (3 times). Afterwards, the product was filtered, washed and dried at $353 \mathrm{~K}$ in air for $6 \mathrm{~h}$, then the product was transferred to
$0.01 \mathrm{~mol} \mathrm{~L}^{-1} \mathrm{Cu}\left(\mathrm{NO}_{3}\right)_{2}$ solution and stirred at $353 \mathrm{~K}$ for one day to get the evaporated product. The product was calcined at $823 \mathrm{~K}$ for $6 \mathrm{~h}$ to obtain $\mathrm{Cu} / \mathrm{MOR}$ (Cu content 4.97 wt.\% for $\mathrm{Cu} / \mathrm{MNPs}$ and 4.99 wt.\% for $\mathrm{Cu} / \mathrm{c}-\mathrm{MOR}$, determined by ICP method). The catalytic condition of $\mathrm{Cu} / \mathrm{MNPs}$ and $\mathrm{Cu} / \mathrm{c}-\mathrm{MOR}$ for SCR of $\mathrm{NO}$ is: [NO]= $\left[\mathrm{NH}_{3}\right]=500 \mathrm{ppm}, 5 \% \mathrm{O}_{2}$, balance=Ar, weight hourly space velocity (WHSV) $=60,000 \mathrm{~mL} \mathrm{~h}^{-1} \mathrm{~g}_{\text {cat. }}{ }^{-1}$.

Proton-type $\mathrm{H} / \mathrm{MOR}$ catalysts were obtained by ionexchange with $\mathrm{NH}_{4} \mathrm{NO}_{3}$ solution for 3 times and then calcined at $823 \mathrm{~K}$ for $6 \mathrm{~h}$. The $\mathrm{Si} / \mathrm{Al}$ and $\mathrm{Si} / \mathrm{Na}$ ratios for $\mathrm{H} / \mathrm{MNPs}$ and H/c-MOR were determined by ICP analysis as shown in Table S1. The reaction condition of disproportionation of toluene is: catalyst, $0.2 \mathrm{~g}$; temperature, $573 \mathrm{~K}$; toluene feed, $1.44 \mathrm{~g} \mathrm{~h}^{-1} ; \mathrm{N}_{2}, 30 \mathrm{~mL} \mathrm{~min}^{-1}$; W/F $=2.2 \mathrm{~g} \mathrm{~h} \mathrm{~mol}^{-1}$.

\section{RESULTS AND DISCUSSION}

MOR zeolites with different morphology and particle size were synthesized at different crystallization temperatures. The smallest particle size of MNPs with size of $\sim 30 \mathrm{~nm}$ was synthesized at $403 \mathrm{~K}$ (Figs S1, S2 and Table S2). Fig. 1a shows the XRD patterns of the calcined MNPs and cMOR (Fig. S3). The XRD pattern of MNPs indicates the formation of an MOR zeolite with broadened Bragg peaks with weaker intensity compared to that of c-MOR, illustrating the decreased size of its individual particles. Fig. $1 \mathrm{~b}$ shows the $\mathrm{N}_{2}$ adsorption-desorption isotherms of MNPs and c-MOR. The c-MOR exhibits a typical I type adsorption isotherm curve, while the MNPs prepared via high concentration of TEAB have large hysteresis loops formed by interparticular porosity occurring at relative pressures $\left(P / P_{0}\right)$ between 0.4 and 1.0. The uptake steps below $P / P_{0}=0.02$ indicate the presence of micropores. The BET surface area and pore volume of MNPs are 




Figure 2 SEM images $(\mathrm{a}-\mathrm{c})$ and TEM images $(\mathrm{d}-\mathrm{f})$ of the calcined MNPs shown in Fig. 1.

$408 \mathrm{~m}^{2} \mathrm{~g}^{-1}$ and $0.3 \mathrm{~cm}^{3} \mathrm{~g}^{-1}$, respectively, higher than that of c-MOR $\left(370 \mathrm{~m}^{2} \mathrm{~g}^{-1}\right.$ and $\left.0.2 \mathrm{~cm}^{3} \mathrm{~g}^{-1}\right)$.

The SEM images show the MNPs assembled into a disk (Fig. 2a, b) with the diameter of $\sim 800 \mathrm{~nm}$ and thickness of $\sim 100 \mathrm{~nm}$. Fig. $2 \mathrm{c}$ indicates that the diameter of irregular MNPs is in the range of $20-40 \mathrm{~nm}$. Transmission electron microscopy (TEM) images (Fig. 2d-f) further confirm that MNPs were self-assembled from ultra-small size of MOR crystals. Fig. 2d shows the low-magnification TEM image taken from two vertical crossed disks. High resolution TEM (HRTEM) images (Fig. 2e, f) show MNPs with high crystallinity and ultra-small size self-assembly into multilevel stacked structures, which is in good line with its crystalline size calculated by Scherrer equation (Table S2) [16].

The size of products decreased with decreasing temperature from 443 to $403 \mathrm{~K}$ due to limited Ostwald ripening (Figs S1, S2 and Table S2). The product was amorphous when the temperature was lower than $403 \mathrm{~K}$ because low temperatures cannot induce the growth of crystal nuclei in four days. The growth of MNPs is limited by the low synthesis temperature, with the main crystallization route being through propagation in the gel. The higher synthesis temperature favors Ostwald ripening, which results in generating larger particles at the expense of smaller ones. From the XRD patterns of the calcined samples, it can be observed that the peak width at half height decreased with increasing the crystallization temperature from 403 to $443 \mathrm{~K}$. The characterization results of the samples synthesized with different $\mathrm{Si} / \mathrm{Al}$ ratios (Fig. S4) show that the pure MOR, mixture of MOR and MFI, and pure MFI zeolites were synthesized with $\mathrm{Si} / \mathrm{Al}$ ratio of
23, 46 and $\infty$, respectively.

In our synthesis system, for the low $\mathrm{Si} / \mathrm{Al}$ ratio (23), it has been found that the crystallization tends to direct the formation of MOR rather than MFI [17]. In addition, the secondary building units of the $4 \mathrm{MR}$ in the MOR structure prefer more $\mathrm{Al}$ atoms with a larger radius as constructing tetrahedrons in comparison to $\mathrm{Si}$ atoms. This is probably because the longer $\mathrm{Si}-\mathrm{O}-\mathrm{Al}$ bond would relax the strain of the $4 \mathrm{MR}$ and make the crystalline structure more thermodynamically and energetically stable [10]. Therefore, it is not conducive to formation of MOR type zeolite with increasing the $\mathrm{Si} / \mathrm{Al}$ ratio. On the other hand, it is easy to form MFI zeolite under high $\mathrm{Si} / \mathrm{Al}$ ratio or without Al. Therefore, the mixture of MOR and MFI and pure MFI zeolites were synthesized with $\mathrm{Si} / \mathrm{Al}$ ratio of 46 and $\infty$, respectively.

The particle size of the samples was decreased from $\sim 100$ to $\sim 35 \mathrm{~nm}$ with increasing TEAB/Si molar ratio from 0 to 0.2 (Fig. S5). However, higher concentrations of TEAB $(\mathrm{TEAB} / \mathrm{Si}>0.2$ ) could not decrease the size of the product. The addition of TEAB is beneficial to synthesize zeolites with small crystal size in the hydrothermal process. TEAB, which easily reacts with the aluminosilicate oligomers, was used as SDA. The high concentration of TEAB would generate numerous nucleation centers. Due to the amount of aluminosilicate was constant, zeolites with small crystal size were generated. The particle size of the samples was decreased with increasing the concentration of TEAB in our synthesis system $[18,19]$.

In comparison to pure TEAB substance, the as-made MNPs show relatively weaker vibration bands $(2,990$, $2,940,1,490$ and $\left.1,390 \mathrm{~cm}^{-1}\right)$ of the $\mathrm{N}^{+}\left(\mathrm{CH}_{2} \mathrm{CH}_{3}\right)_{4}$ groups, 

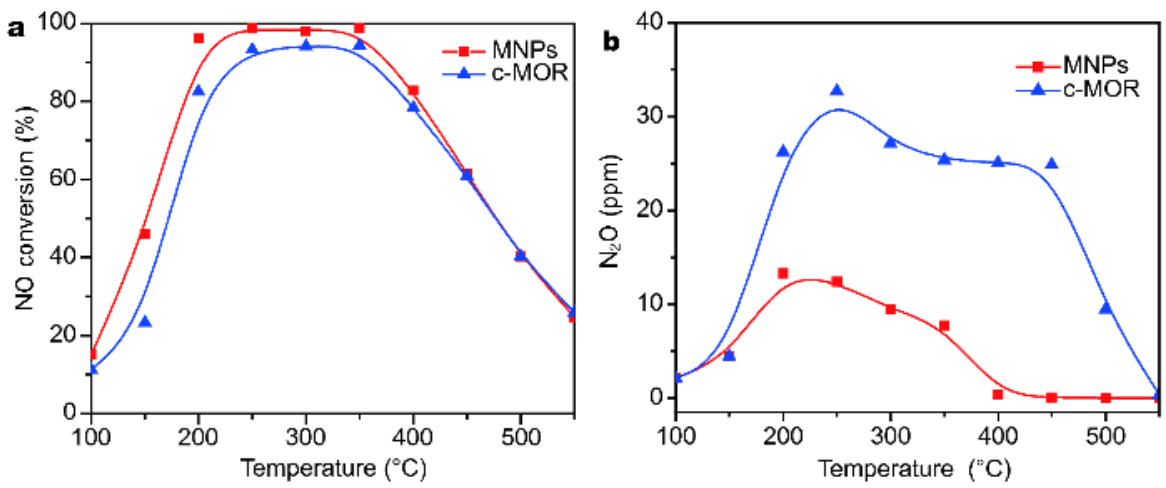

Figure 3 (a) $\mathrm{NO}_{x}$ conversion over $\mathrm{Cu} / \mathrm{MNPs}$ (red) and $\mathrm{Cu} / \mathrm{c}-\mathrm{MOR}$ (blue). Reaction condition: $[\mathrm{NO}]=\left[\mathrm{NH}_{3}\right]=500 \mathrm{ppm}, 5 \% \mathrm{O}_{2}$, balance $=\mathrm{Ar}$, WHSV= $60,000 \mathrm{~mL} \mathrm{~h}^{-1} \mathrm{~g}_{\text {cat. }}{ }^{-1}$. (b) $\mathrm{N}_{2} \mathrm{O}$ yield over $\mathrm{Cu} / \mathrm{MNPs}$ (red) and $\mathrm{Cu} / \mathrm{c}-\mathrm{MOR}$ (blue).

indicating that the $\mathrm{N}$ atom of TEAB is strongly bonded with $\mathrm{T}(\mathrm{Si}$ or $\mathrm{Al})$ atom in MNPs (Fig. S6). Therefore, TEAB works as a SDA that directs polymerization between aluminosilicate oligomers or between aluminosilicate and silicate oligomers during nucleation of zeolite. MNPs have a composition of $\mathrm{Na}_{4} \mathrm{TEA}_{m} \mathrm{Al}_{5} \mathrm{Si}_{43} \mathrm{O}_{96} \cdot 6 \mathrm{H}_{2} \mathrm{O} \cdot(2$ $-m) \mathrm{TEAB}(m \approx 1)$, with some $\mathrm{TEA}^{+}$to balance the charge, according to the $\mathrm{Si} / \mathrm{Al}$ ratio of 9.2 , weight loss of intercrystalline water $(3.2 \%)$ and TEAB $(8.8 \%)$ characterized by ICP and TGA (Fig. S7), respectively.

The $12 \mathrm{MR}$ large-pores along $c$-axis were occupied by TEAB molecules as simulated by Weckhuysen and coworkers [20]. It can be deduced that the high concentration of TEAB could generate abundant crystal nuclei resulting in smaller crystals. The crystal nuclei templated by TEAB block the growth of crystal along $c$-axis, which results in the formation of small crystals. As a result, the growth of MNPs is limited by the high concentration of TEAB and low synthesis temperature.

As we all know that, for catalytic application, the diffusion limitation of reactants and products is very serious especially for MOR zeolite with $12 \mathrm{MR}$ main channels. To demonstrate the catalytic advantage of the ultra-small MNPs, the SCR of NO with $\mathrm{NH}_{3}$ as reductant was selected as the model reaction after supported $\mathrm{Cu}$ active species. From the catalytic performances of $\mathrm{Cu} / \mathrm{MNPs}$ and $\mathrm{Cu} / \mathrm{c}-\mathrm{MOR}$ (Fig. 3a), it can be seen that $\mathrm{Cu} / \mathrm{MNPs}$ show higher catalytic activity and wider temperature window than $\mathrm{Cu} / \mathrm{c}-\mathrm{MOR}$, especially display higher activity at low temperatures. For $\mathrm{Cu} / \mathrm{MNPs}$, the conversion of $\mathrm{NO}$ at 150 and $200^{\circ} \mathrm{C}$ is $\sim 50 \%$ and $\sim 100 \%$ much higher than $\sim 15 \%$ and $\sim 80 \%$ of $\mathrm{Cu} / \mathrm{c}-\mathrm{MOR}$, respectively. Improved $\mathrm{NO}$ catalytic performances of $\mathrm{Cu} / \mathrm{MNPs}$, especially at low temperature, would be due to well dispersion of $\mathrm{Cu}^{2+}$ and without diffusional limitation for reactants and products, resulting from shorter transmission path and higher specific surface area of ultra-small crystals [21]. Fig. $3 \mathrm{~b}$ shows that $\mathrm{N}_{2} \mathrm{O}$ as by-product increases and then turns to decrease with increasing temperature; in addition, MNPs have better selectivity than c-MOR because of less of the by-product $\mathrm{N}_{2} \mathrm{O}$. MNPs possess larger specific surface area and almost no diffusional limitation for reactants and products due to the small particle size, which results in more $\mathrm{NO}$ transformed to $\mathrm{N}_{2}$ rather than $\mathrm{N}_{2} \mathrm{O}$.

Since H/MOR is widely used as an important commercial catalyst in industrial processes of toluene disproportionation, thus we have carried out the disproportionation of toluene. According to the catalytic performance of H/MNPs and H/c-MOR (Table S4), the toluene conversion over two MOR zeolites decreased with prolonging reaction time but the nanosized MOR was still more stable than c-MOR against deactivation. For $\mathrm{H} /$ MNPs, the conversion of toluene at time on stream of $2 \mathrm{~h}$ was $8.9 \%$, much higher than $2.5 \%$ of $\mathrm{H} / \mathrm{c}-\mathrm{MOR}$. MNPs exhibited excellent performance for disproportionation of toluene than c-MOR due to shorter transmission path and higher specific surface area of ultra-small crystals.

\section{CONCLUSIONS}

A series of MOR with different particle sizes have been prepared by controlling crystallization temperature and concentration of TEAB. The variation of $\mathrm{Si} / \mathrm{Al}$ ratios would result in different type of zeolites. Highly crystalline MOR was successfully obtained with crystal size of $\sim 30 \mathrm{~nm}$ by increasing the TEAB concentration to provide more nucleation and lowering the temperature to limit Ostwald ripening. This material exhibits higher conversion and catalytic activity at low temperature than c-MOR for SCR of $\mathrm{NO}_{x}$ and also shows higher catalytic activity 
and longer lifetime for disproportionation of toluene than c-MOR due to the short transition path and high specific surface area $\left(408 \mathrm{~m}^{2} \mathrm{~g}^{-1}\right)$. This finding would open up new possibilities for the elaborate fabrication of nanometer-sized zeolites.

Received 12 January 2018; accepted 21 March 2018; published online 20 April 2018

1 Corma A. From microporous to mesoporous molecular sieve materials and their use in catalysis. Chem Rev, 1997, 97: 2373-2420

2 Davis ME. Ordered porous materials for emerging applications. Nature, 2002, 417: 813-821

3 Davis ME. Zeolites from a materials chemistry perspective. Chem Mater, 2014, 26: 239-245

4 Li Y, Yu J. New stories of zeolite structures: their descriptions, determinations, predictions, and evaluations. Chem Rev, 2014, 114: 7268-7316

5 Mintova S, Gilson JP, Valtchev V. Advances in nanosized zeolites. Nanoscale, 2013, 5: 6693-6703

6 Xue Z, Ma J, Zhang T, et al. Synthesis of nanosized ZSM-5 zeolite with intracrystalline mesopores. Mater Lett, 2012, 68: 1-3

7 Ng EP, Chateigner D, Bein T, et al. Capturing ultrasmall EMT zeolite from template-free systems. Science, 2012, 335: 70-73

8 Awala H, Gilson JP, Retoux R, et al. Template-free nanosized faujasite-type zeolites. Nat Mater, 2015, 14: 447-451

9 Meier W, Kristallogr Z. The crystal structure of mordenite (ptilolite). Zeitschrift für Kristallographie-Crystalline Mater, 1961, 115: 439-450

10 Lv A, Xu H, Wu H, et al. Hydrothermal synthesis of high-silica mordenite by dual-templating method. Microporous Mesoporous Mater, 2011, 145: 80-86

11 Ren L, Guo Q, Zhang H, et al. Organotemplate-free and one-pot fabrication of nano-rod assembled plate-like micro-sized mordenite crystals. J Mater Chem, 2012, 22: 6564-6567

12 Zhang $\mathrm{H}$, Zhang $\mathrm{H}$, Wang $\mathrm{P}$, et al. Organic template-free synthesis of zeolite mordenite nanocrystals through exotic seed-assisted conversion. RSC Adv, 2016, 6: 47623-47631

13 Yang Y, Ding J, Xu C, et al. An insight into crystal morphologydependent catalytic properties of MOR-type titanosilicate in liquid-phase selective oxidation. J Catal, 2015, 325: 101-110
14 Jo C, Jung J, Shin HS, et al. Capping with multivalent surfactants for zeolite nanocrystal synthesis. Angew Chem, 2013, 125: 1019810201

15 Kim GJ, Ahn WS. Direct synthesis and characterization of high$\mathrm{SiO}_{2}$-content mordenites. Zeolites, 1991, 11: 745-750

16 Buerger MJ, Azaroff LV. The Powder Method in X-Ray Crystallography. New York: McGraw-Hill, 1958

17 Kim SD, Noh SH, Seong KH, et al. Compositional and kinetic study on the rapid crystallization of ZSM-5 in the absence of organic template under stirring. Microporous Mesoporous Mater, 2004, 72: 185-192

18 Li J, Li Z, Han D, et al. Facile synthesis of SAPO-34 with small crystal size for conversion of methanol to olefins. Powder Tech, 2014, 262: 177-182

19 Bohström Z, Arstad B, Lillerud KP. Preparation of high silica chabazite with controllable particle size. Microporous Mesoporous Mater, 2014, 195: 294-302

20 Schmidt JE, Fu D, Deem MW, et al. Template-framework interactions in tetraethylammonium-directed zeolite synthesis. Angew Chem Int Ed, 2016, 55: 16044-16048

21 Sultana A, Nanba T, Sasaki M, et al. Selective catalytic reduction of $\mathrm{NO}_{x}$ with $\mathrm{NH}_{3}$ over different copper exchanged zeolites in the presence of decane. Catal Today, 2011, 164: 495-499

Acknowledgements This work was supported by the National Natural Science Foundation of China (21533002 and 21571128), the National Excellent Doctoral Dissertation of China (201454), and the National Key R\&D Program of China (2016YFC0205900).

Author contributions Che S designed the experiment and led the project. Xu Y synthesized the ultra-small mordenite zeolite nanoparticles and performed the SEM, XRD, TG, IR, $\mathrm{N}_{2}$ adsorption-desorption measurements. Shen $\mathrm{X}$ performed the TEM measurement, Ma $\mathrm{Y}$ and Peng $\mathrm{C}$ measured the catalytic properties of materials. Xu Y wrote the paper with support from Che S, Peng H, Wu P and Han L. All authors contributed to the general discussion.

Conflict of interest The authors declare that they have no conflict of interest.

Supplementary information Experimental details are available in the online version of the paper. 


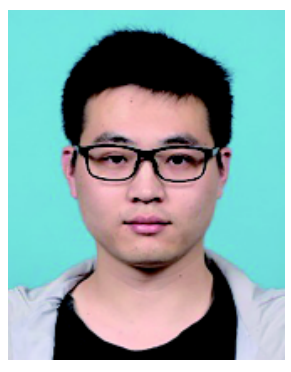

Yi Xu received his BSc degree in chemistry from Donghua University in 2015. He joined Prof. Che's group as a master candidate in 2015. His research interests focus on the design and synthesis of hierarchical zeolitic materials.

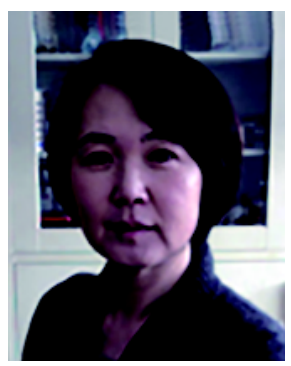

Shunai Che is a professor in the Department of Chemistry, School of Chemistry and Chemical Engineering, Shanghai Jiao Tong University. She received her PhD degree from Yokohama National University. She was a guest researcher at Saitama University and worked as a postdoctoral fellow at Yokohama National University. Her research interests encompass the development of chiral inorganic materials and porous materials with novel structures and functions in view of applications in optical devices and heterogeneous catalysis.

\section{合成超小MOR型分子篮纳米颗粒}

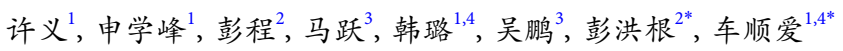

摘要 本文在一个较低的温度 $(403 \mathrm{~K})$ 下使用四乙基溴化铵(TEAB)为模板剂合成出超小的 $(30 \mathrm{~nm}) \mathrm{MOR}$ 型分子䇥. 超小的产物粒径是由于 高浓度的TEAB可以提供更多的晶核以及低温限制了奥氏熟化. 产物在低温区域的 $\mathrm{NO}_{x}$ 选择性催化还原活性远远高于传统MOR型分子節. 此外, 超小的纳米颗粒减小了物质的传输限制以及较大的比表面积使得其在甲苯歧化反应中具有比传统MOR更高的催化活性和耐失活 性. 